\title{
Pedagogical technologies of machine translation skills forming on the example of bachelor students specializing in mechatronics and robotics at Don State Technical University
}

\author{
Irina Gritsay ${ }^{1}$ and Liubov Vodyanitskaya* \\ Don State Technical University, 344000, Rostov-on-Don, Russia
}

\begin{abstract}
In this paper the authors took into consideration professional training of specialists who can use technical documentation in a foreign language. The definition of machine translation, its value, main advantages and disadvantages were examined. This research showed the importance of machine translation and the need to train students of technical specialties in MT skills. The model of a special program for training students and its theoretical and practical parts were described. Based on the results of the error analysis, the error types were categorized into 3 categories. The results of the tests were analysed and shown in the tables. A significant decrease in the number of errors was noted. Based on the findings, pedagogical implications were discussed regarding how teachers can successfully and effectively incorporate MT into the classroom studies.
\end{abstract}

\section{Introduction}

The need to speak a foreign language for an engineer with a higher technical education has become particularly important nowadays. An urgent task for the technical university is the professional training of specialists who can read technical documentation in a foreign language, establish contacts with foreign enterprises, and promote the products of their enterprise abroad.

The result of teaching a foreign language at a technical university is not the assimilation of language knowledge, but the formation of practical skills and competencies among students. "Students' acquisition of communicative competence is focused on the formation of a level of foreign language proficiency that will allow them to use it to meet professional needs, implement personal and business contacts, and further self-education."

The global translation market has experienced sustained growth over the last decades, and although actual estimates of the growth rate may differ between sources, the trend finds confirmation in research reports, anecdotal evidence and official forecasts issued by professional organisations" [1].

\footnotetext{
* Corresponding author: fleur0707@rambler.ru
} 
Machine translation can be defined as the process of translating texts from one natural language to another with a help of a special computer program. It is also called the direction of scientific research related to the construction of such systems.

Great attention to teaching MP is paid all over the world. Among them such authors as Michelle Lee, Cynthia Ducar, Mariusz Marczak [2], [3], [4] should be mentioned.

In recent years, marked gains in the accuracy of machine translation (MT) outputs have greatly increased its viability as a tool to support the efforts of English as a foreign language (EFL) students to write in English [5].

With the development of information technologies a lot of programs and Internet services which can be used for translations of various texts have been developed.

High speed of MT is one of the main advantages of machine translators. Since the translation is carried out by a computer, it can process a large amount of information in seconds whereas it may take a specialist several hours to translate. But anyone who has ever tried to translate a technical text using an online translator knows that the result is usually not very similar to original text and coherent human speech. That is why machine translation always requires editorial revision and human correction.

Besides automatic translation requires less financial investment or does not require it at all. If paid software is used for translation you need to buy it. If you need to translate a simple text, then you can use free online translator.

Machine translation is more secure. As a general rule, the more people who have access to a document, the higher the security risks. By reducing the number of humans who have to access to sensitive data, machine translation can improve data security.

The aim of this research is to show the importance and great advantage of machine translation and the need to train students of technical specialties in MT skills. The authors of this paper address to one of the main pedagogical issue which has arisen in our time - the use of machine translation in teaching students though it is unwelcomed by language teachers and even considered as a form of cheating. "The current situation can be summarized as follows: the demand for MT is increasing in the learning context, but the reliability of MT has not yet been fully established. Therefore, we need to determine how best to use MT, an imperfect tool, to produce positive learning outcomes in the language classroom [6].

The methods. In this study, the comparative analysis method and the experimental method were used.

Teaching a foreign language at Automation, mechanization and control faculty was carried out as follows:

According to the Federal State Educational Standard for Higher Education in the field of training 221000 Mechatronics and robotics (qualification degree "bachelor"), the graduate must have the following general cultural competence OK7

- the ability to speak one of the foreign languages at a level not lower than spoken,

- as a result of training, the student must know: lexical minimum in the amount of 4000 general knowledge educational lexical units of technical and technological character (for a foreign language);

- ability to speak a foreign language to the extent necessary to be able to obtain information from foreign sources [6].

\section{Description of experiment}

A special attention is paid to such kind of work, when students prepare speeches and reports for the International Scientific and Practical Conference of Students, Postgraduates and Young Scientists, which is held annually at Don State Technical University on the basis of the Department "Scientific and Technical Translation and Professional 
Communication", write articles in the collection "Information and Communication Culture: Science and Education", make abstracts and annotations of articles, select a bibliography. However, the student curriculum does not include the formation of such a competence as machine translation. Undoubtedly, students are increasingly using MT for diverse academic purposes as well as in their daily lives. They use MT for vocabulary learning, translation, reading comprehension, and writing assignments, considering it to be a good supplementary tool for language learning [7].

The authors of this paper developed a special training program for teaching translation skills the technical students of the faculty Automatization, Mechatronics and Control.

The model of a special program for training students of a technical specialty in machine translation skills is made up of 2 parts: theoretical and practical.

The theoretical part of this program describes the problems and difficulties of using MT for translating special texts and technical documentation. The practical part includes questions from the correct preparation of the text for machine translation to the ability to create and use Databases and the ability to use a professional machine translator TRADOS.

Accoding to that program at the first lesson the students compared 5 different machine translators: Google Translate, Microsoft BING translator, Yandex translator, Prompt 18 and TRADOS. After a thorough review of the advantages and disadvantages of the abovementioned translators, Trados was chosen for a more complete study and practical use.

The students' task was to compare MT to paper and electronic dictionaries and other machine tools. After completing it they came to the conclusion that MT performed better in

0 translating technical terms, phrases and abbreviations than traditional dictionaries.

The next step in teaching MT skills was the studying of permutations during translation.

One of the most important stages of translation from one language to another is to change the word order. In Russian linguistics, this phenomenon has been given the name grammatical transformations in English-language literature, the terms word reordering and distortion of grammatical permutations for each individual language pair is a key link in the construction of statistical machine translation systems. Within the framework of statistical machine translation, the phenomenon of word permutation is mainly analyzed and modeled from a mathematical point of view. Nevertheless, to understand the processes occurring at the level of sentence structure in translation, it is necessary to involve such a fundamental property of the source and target languages as their characteristic word order.

A permutation as a type of translation transformation can be defined as a change in the location (order of sequence) language elements in the translation text compared to the original text. Elements that can be rearranged: words, phrases, parts of a complex sentence, independent sentences.

The students must study carefully the difference of word order in English and Russian languages.

Word order is one of the most important and essential characteristics of the grammatical structure of a sentence in any language. T.V. Zherebilo defines word order as a typical relative arrangement of word forms in their specific functions - the subject predicate, etc. [8] Dictionary of Linguistic Terms. In linguistics, word order is usually understood as the relative position of the three main members of a sentence - the subject, the predicate, and the object.

"As a rule, a sentence in English begins with a subject or a group of subjects, followed by a predicate or a group of predicates. For the English language, it is characteristic that in the first place - rema. Secondary information such as an adverbial modifier of place and attendant circumstances are located at the end of the sentence" [9].

Another important difference that determines the use of permutation in translation is the free place of an adverbial modifier of time in the Russian sentence, as opposed to the 
English one, where the place of adverbial modifier of time, regardless of the actual division, tends to be framed: at the beginning or at the end (the most important one).

Words, phrases, parts of a complex sentence, elementary sentences within a complex sentence, and independent sentences in the system of the whole text are rearranged. Permutation is usually used when the sequence of elements, with a common meaning, is determined by different speech traditions and conditions [10].

\section{Data analysis}

The students studying machine translation of technical texts were given several technical texts in Russian, which they had to change the word order in accordance with the grammatical rules and norms of the English language [11]. Most of the students showed good results in this task.

The students paid special attention to the policemy of words, which should never be forgotten when translating technical documentation and literature. It should be a rule to use special technical dictionaries that correspond to the subject of the translated text. Much attention of the teachers was paid to the formation of students ' skills in creating and using their own databases, into which students must constantly enter terms corresponding to the specialty they are studying at the universities [12]. Translation of terminology is one of the most important difficulties which students might face while translating technical documentation. During the semester students studied the concept of a term, the main challenges in translating terms and ways to overcome them. A term is a word, phrase, acronym or another lexical unit, both meaningful corresponding extra linguistic concept in real the world. Industry specific terminology requires a translator who has experience within that industry, that why it is necessary to train future engineers in skills of MT. The user of a machine translator can do a lot to optimize MT quality. Terminology management is the first building block in this process. Term extraction methods can help to build mass from scratch when there are no databases yet [13]. Apart from the technical aspects that are best left to the respective tool vendors, the MT term base is created, it should be used along with authoring tools and to produce high-quality texts with consistent terminology. Existing texts that do not meet the requirements of consistent terminology should be checked for term variances as a basis for normalization, which aims at the usage of one and the same term for one concept in the text [14]. The process of terminology optimization in translation workflows strongly depends on the systems and interfaces in use, so solutions may change from customer to customer. As systems constantly improve we must study all the changes and opportunities which bring improvements to translation environments and translation itself [15].During an experiment conducted by the authors, 30 students of group UMR 11 were offered technical text for translation before they were taught the theoretical part of this program. We thourougly studied these translations and identified three types of errors typical for the translations completed by the students without using a machine translator which are - content identity of a translated text, grammar mistakes and lexical mistakes. The lexical mistakes are using a wrong word or a term which does not collocate with another part of sentence. They might arise due to the native language interference. Besides lexical mistakes include orthographic errors and semantic lexical errors. The grammar errors involve faulty structures which may include agreement errors, tense errors ,number error (plural-singular), prepositional errors, articles and conjunction errors. All the abovementioned mistakes may lead to distorting information and thus misinforming the recipient. After having studied the theoretical part of the program the students were given other texts for translation and the number of mistakes made in the translation of these texts has significantly decreased. The results of the research are shown in the grafs (Fig. 1, 2, 3). 
The most widespread grammar errors in students` translation before introducing MT translation included - agreement errors. The examples are taken from students` translations.

1. Robotics are based on two related technologies.

2. Mechatronics are a multidisciplinary branch of engineering.

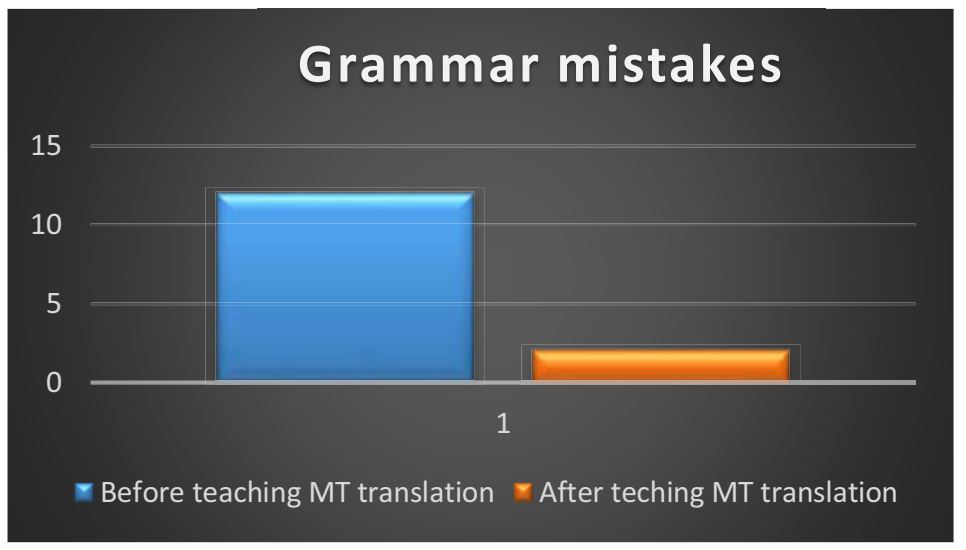

Fig. 1. Grammar mistakes

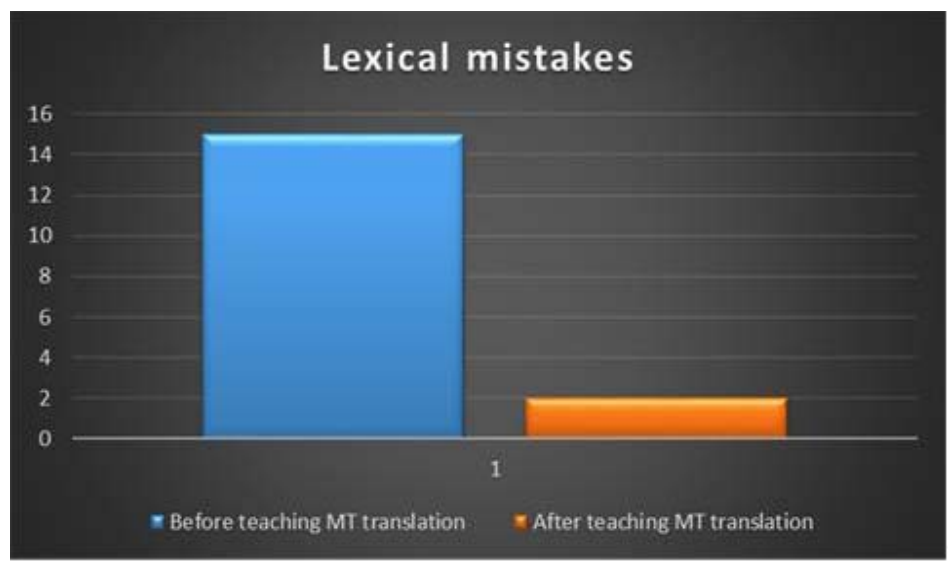

Fig. 2. Lexical mistakes

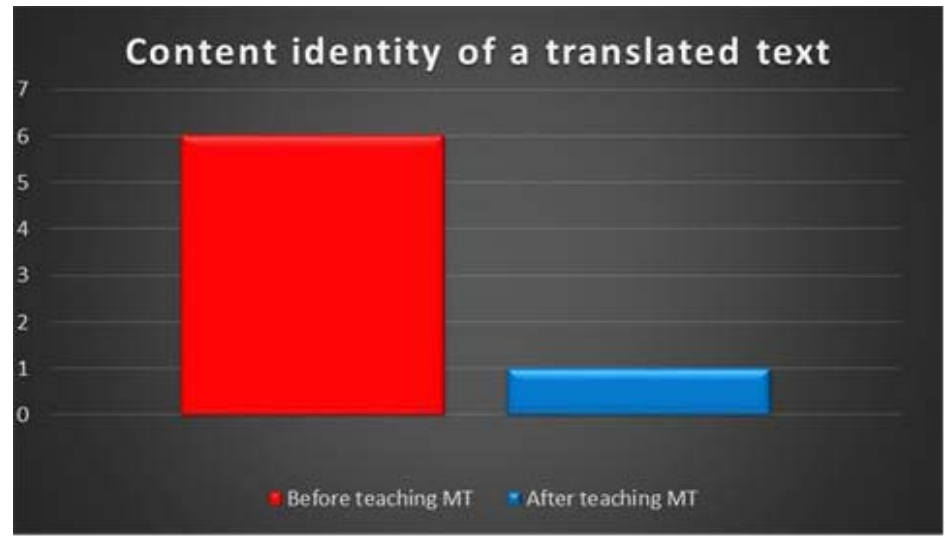

Fig. 3. Content identity of a translated text 


\section{Conclusion}

The role of MT is expected to increase over the next few years due to the development of technologies and artificial intelligence therefore there is an urgent need to be able to use MT tools properly and to the fullest extent. The research conducted by the authors proved the efficacy and liability of teaching MT at technical universities. The results of study and data analysis have shown a significant decrease in a number of mistakes made by students along with the lack of information distortion while translating technical texts using MT. Moreover it took students less time to complete the translation tasks using MT which led to a high productivity. Besides on seeing good results of the work students became more involved in a translation process. The work with MT has created interest among students and motivated them to deepen language knowledge. This study has given the evidence of an importance of MT implementation in the educational process. Thus we come to conclusion that using MT during classes at technical university is an effective tool for achieving educational goals.

\section{References}

1. Marius Marczak, New Perspectives on the Anglophone world, 7 (2018).

2. Nathalia da Cruz Alves, Christiane Gresse von Wangenheim, Lucia Helena Martins pachero, Informatics in education 20 (1), 19-45 (2021).

3. Ivan Koralov, Informatics in education 4 (1), $43-48$ (2005).

4. Cynthia Ducar Deborah Houk Schocket, Machine translation and the L2 classroom: Pedagogical solutions for making peace with Google translate (2018)

5. Michelle Lee, Neil Briggs, Effects of using machine translation to mediate the revision process of Korean university students' academic writing (2020).

6. Lívia S. Marques, Christiane Gresse von Wangenheim, Jean C. R. HAUCK,

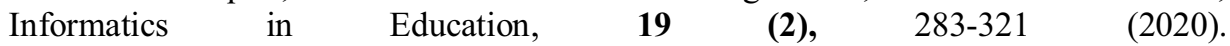
https://doi.org/10.15388/infedu.2020.14

7. E.V. Krasnova, V.V. Pankova, Zh.E. Bronzova, Innovative educational technologies and teaching methods: monograph, (2014)

8. Tatyana Jherebilo, Dictionary of linguistic terms, (2010).

9. D.V. Minakova, E.V. Krasnova, Don's young scientist 4 (7), 2 -19 (2017).

10. Sangmin-Michelle Lee, Computer assisted language learning 1, (2019).

11. R. Sennrich, B. Haddow, and Birch, In NAACL HLT, The 2016 Conference of the North American Chapter of theAssociation for Computational Linguistics: Human Language Technologies, San Diego California, USA, June 12-17, 35-40, (2016).

12. Anthony Pym, Translation and Interpreting 3 (1), 1-9 (2011).

13. S. O’Brien, Translation Spaces 1 (1), 101-122 (2012).

14. Odactoglu, Mehmet Cem, Saban Kokturk, Social and Behavioral Sciences 197, 10851094 (2015).

15. John Oladosu, et al. Approaches to machine translation: Areview. FUOYE, J. Eng. Technol. 1(1), 120-126 (2016). 